Note

\title{
Movement of Heterorhabditis amazonensis and Steinernema arenarium in search of corn fall armyworm larvae in artificial conditions
}

\author{
Vanessa Andaló ${ }^{*}$, Viviane Santos², Grazielle F. Moreira ${ }^{3}$, Camila Moreira ${ }^{4}$, Marcela Freire ${ }^{5}$, Alcides Moino Jr. ${ }^{5}$
}

${ }^{1}$ IFMG - Campus Bambuí, C.P. 05 - 38900-000 - Bambuí, $M G$ - Brasil.

2USP/ESALQ - C.P. 09 - 13418-900 - Piracicaba, SP - Brasil.

${ }_{3}$ UNESP/FCAV - Via de Acesso Prof. Paulo Donato

Castellane, $\mathrm{s} / \mathrm{n}$ - 14884-900 - Jaboticabal, SP - Brasil.

${ }^{4} \mathrm{UFV}$ - Av. Peter Henry Rolfs, s/n - 36570-000 - Viçosa,

$M G$ - Brasil.

${ }^{5}$ UFLA - C.P. 3037 - 37200-000 - Lavras, MG - Brasil.

*Corresponding author <vanessaandalo@yahoo.com.br>

Edited by: Richard V. Glatz

Received January 21, 2011

Accepted December 21, 2011
ABSTRACT: Spodoptera frugiperda (Smith, 1797) (Lepidoptera: Noctuidae) is considered to be the main pest of maize crops in Brazil. Entomopathogenic nematodes (EPN) may be used to control this pest and exhibit different, unique abilities to search for their hosts. The movement of EPN in relation to $S$. frugiperda was evaluated. To test for horizontal movement, a styrofoam enclosure filled with sand was divided into segments, nematodes were placed at the entrance to the enclosure and a larva was placed at the end of each division. The same approach was used to evaluate vertical movement; however, PVC pipes were used in this case. In general, the mortality was inversely proportional to the initial distance between host and nematodes. In the vertical displacement test, both nematodes were able to kill the larvae up to a distance of 25 $\mathrm{cm}$. Therefore, the infective juveniles of $H$. amazonensis and $S$. arenarium can search out, infect and kill larvae of $S$. frugiperda at distances of up to $60 \mathrm{~cm}$ and $25 \mathrm{~cm}$ of horizontal and vertical displacement, respectively.

Keywords: Spodoptera, biological control, behaviour, strategy, entomopathogenic

\section{Introduction}

The ability of entomopathogenic nematodes (EPN) infective juveniles to disperse actively in soil and to locate the host is fundamental to the successful application of many species of these organisms (Cutler and Webster, 2003). The corn fall armyworm Spodoptera frugiperda (Smith, 1797) (Lepidoptera: Noctuidae) is a pest that may potentially be controlled by using EPN. Spodoptera frugiperda occurs in environments that provide concealment, e.g., in the corncob and in the soil (as pupae). The corncob and the soil both represent potential sites for the use of these nematodes (Fuxa et al., 1988).

The nematode's host search behaviour and its infective capacity are both affected by many factors. These factors include soil characteristics (e.g., soil texture and moisture) (Kaya, 1990) and the infective juveniles search strategy ("ambush" versus "cruiser") (Lewis et al., 1992; Grewal et al., 1994). Accordingly, the objective of this study is to evaluate the movement of Heterorhabditis amazonensis RSC2 and Steinernema arenarium A11 in search of $S$. frugiperda. This information is intended to partially characterize the abilities of these two species of EPN to search for this insect pest, since it is stated that EPN have the ability to infect, kill and reproduce inside Spodoptera frugiperda larvae (Fuxa et al., 1988; Garcia et al., 2008).

\section{Materials and Methods}

Multiplication and maintenance of the entomopathogenic nematodes

The nematodes were obtained from a laboratory bank at University of Lavras (MG), Brazil, and were main- tained in Erlenmeyer flasks in acclimated chambers at a temperature of $16 \pm 1{ }^{\circ} \mathrm{C}$, in an aqueous suspension with 500 to 1,000 infective juveniles $\mathrm{mL}^{-1}$. Heterorhabditis amazonensis RSC2 was identified by morphological and molecular techniques and $S$. arenarium by morphological techniques. The nematodes were grown on Galleria mellonella larvae (Linnaeus, 1758) (Lepidoptera: Pyralidae) which were raised according to the methodology described by Dutky et al. (1964), using an artificial diet modified by Parra (1998). The nematode culture and maintenance followed the methodology described by Molina and López (2001). Decantation was performed to separate the fatty insect bodies from the infective juveniles. After completion of the nematode suspension purification process, these purified suspensions were diluted and quantified using a stereoscopic microscope.

\section{Spodoptera frugiperda growth}

To establish the initial $S$. frugiperda colony, larvae were collected from areas of maize cultivars in the region of Lavras (MG), Brazil. The larvae were then placed into test tubes $15 \mathrm{~cm}$ in height and $1.5 \mathrm{~cm}$ in diameter containing an artificial diet (Bowling, 1967). After the larvae pupated, they were transferred to PVC pipes of $10 \mathrm{~cm}$ in diameter and $20 \mathrm{~cm}$ in height, with the pipe extremities plugged with a voile-type fabric and sealed with a rubber band. The pipes were coated internally with filter paper onto which the moths could oviposit once emerged as adults. The moths were fed daily with $10 \%$ honey placed in the pipe on pieces of cotton to facilitate access to the food. The egg masses were transferred to sterilised Petri dishes with an artificial diet. Newly hatched caterpillars were collected and individually placed in test tubes with the same diet. 


\section{Horizontal movement in a sand column}

The G. mellonella larvae were used as a default host in the horizontal and vertical displacement tests. This insect larva is the standard bait used for the majority of isolations of soil nematodes in the soil. The results of these tests would then serve to compare the EPN-caused mortality of G. mellonella larvae and of $S$. frugiperda larvae.

To evaluate the horizontal displacement of the EPN species $H$. amazonensis and $S$. arenarium when searching for $G$. mellonella and $S$. frugiperda larvae, a Styrofoam enclosure ( $80 \mathrm{~cm}$ long, $20 \mathrm{~cm}$ wide and $10 \mathrm{~cm}$ high) was set up. This enclosure was divided into five parts by placing pieces of Styrofoam at distances of 10, 20, 40,60 and 80 $\mathrm{cm}$ from the opening (Figures $1 \mathrm{~A}$ and $1 \mathrm{~B}$ ). Entomopathogenic nematodes forage for their hosts in various ways and can exhibit cruiser or ambusher behavior (Lewis, 2002; Lewis et al., 2006; Stuart et al., 2006). In our experiments, the distance $80 \mathrm{~cm}$ length was chosen as the maximum initial distance between nematode and host, as was deemed sufficient to assess cruiser type foragers. Some heterorhabditids can be found in deeper soil layers (up to $40 \mathrm{~cm}$ below ground) (Glazer, 2002), showing the potential for displacement in soil.

As a substrate for the movement of the EPN, autoclaved medium sand (particle sizes 0.25 to $0.5 \mathrm{~mm}$ ) was used for the entire length of the enclosure. The sand height in the enclosure was $8 \mathrm{~cm}$. Each enclosure held a total of $3.8 \mathrm{~kg}$ of sand, $475 \mathrm{~g}$ for each $10 \mathrm{~cm}$. For each 10 $\mathrm{cm}$ of distance along the enclosure, $100 \mathrm{~mL}$ of water were added to sand, a total of $800 \mathrm{~mL}$ for the entire enclosure. So, the moisture level was $210 \mathrm{~mL}$ of water per $\mathrm{kg}$ of sand. This moisture level was chosen to allow complete moistening of sand in the arenas without soaking or dry areas.

Nematodes were applied to the enclosure opening in $10 \mathrm{~mL}$ of a suspension at a concentration of 500 infective juveniles $\mathrm{mL}^{-1}$. One larva of $G$. mellonella or $S$. frugiperda was placed in a $3 \times 3 \mathrm{~cm}$ cage (made of high density polyethylene with mesh diameter $0.2 \mathrm{~cm}$ ) (Figure $1 \mathrm{C})$, at the end of the desired distance for displacement of the nematode. Control treatments were made in two ways: i) water alone was applied (no infective juvenile suspension), and ii) no larvae were released. To extract infective juveniles from sand a 150 mesh sieve was used over a 500 mesh sieve. The infective juveniles retained on the bottom sieve were collected. The enclosures were maintained in a greenhouse with an average temperature of $20.2{ }^{\circ} \mathrm{C}$ and air of $58 \%$ relative humidity.

Ten replicates were used for each distance and for each host insect. The larval mortality was estimated six days after releasing the nematodes. Only a minimal amount of mortality would occur after six days, since infective juveniles cause mortality between 24 to $48 \mathrm{~h}$ after infection (Adams \& Nguyen, 2002). Mortality caused by infective juveniles was confirmed by dissecting the larvae and verifying the presence of nematodes in the dead larvae. The mortality data obtained were subjected to analysis of variance (ANOVA) and to a Tukey comparison test $(p<0.05)$.

\section{Vertical displacement in a sand column}

The vertical movement test was conducted in a sand column using $H$. amazonensis and $S$. arenarium nematodes and $G$. mellonella and $S$. frugiperda hosts. To set up the sand column, pieces of PVC pipe $15 \mathrm{~cm}$ in diameter and 5 $\mathrm{cm}$ in depth were used. A plastic screen was placed at the base of the pipes. Each piece of pipe was filled with sand. The pipes were stacked vertically to reach the desired depth. The piece of pipe at the base of the stack received the host insect larvae to be tested. The larvae were placed in a $3 \times 3 \mathrm{~cm}$ cage (made of high density polyethylene with mesh diameter $0.2 \mathrm{~cm}$ ). The tested depths were $5,10,15$, 20 and $25 \mathrm{~cm}$. Adhesive tape was used to fasten the pieces of pipe together (Figure 2).

When the pipes were filled, $1.2 \mathrm{~kg}$ of sand was used per piece of pipe. The sand filled the pipe up to the end and formed a column $5 \mathrm{~cm}$ in depth. The sand was moistened with water, so that for each $5 \mathrm{~cm}$, or for each piece of pipe, $200 \mathrm{~mL}$ were added. The moisture level chosen to allow complete moistening of sand in the arenas without soaking or dry areas was $167 \mathrm{~mL}$ of water per $\mathrm{kg}$ of sand.

The nematodes were applied to the pipe at the upper end of the column in a $10 \mathrm{~mL}$ suspension at a concentration of 500 infective juveniles $\mathrm{mL}^{-1}$. Two control treatments were prepared: i) water alone was applied, not applying infective juvenile suspension, and ii) larvae were not released. A 150 mesh sieve was used over a 500 mesh sieve to extract infective juveniles from the sand. The infective juveniles retained on the bottom sieve were collected.

Columns were maintained in a greenhouse with an average temperature of $20.2^{\circ} \mathrm{C}$ and a relative humidity of $58 \%$. Ten replicates were performed per treatment. The evaluation was made after six days dismantling the columns and verifying the mortality of the larvae. Mortality caused by infective juveniles was confirmed by dissecting the larvae and verifying the presence of nematodes in the dead larva. The mortality data obtained were subjected to analysis of variance (ANOVA) and to a Tukey comparison test $(p<0.05)$.

\section{Results}

\section{Horizontal displacement in the sand enclosure}

The infective juveniles of $H$. amazonensis and $S$. arenarium were capable of causing mortality at distances of 10 to $60 \mathrm{~cm}$ from the hosts. However, when larvae of $G$. mellonella and $S$. frugiperda were placed $80 \mathrm{~cm}$ from the infective juveniles, the nematodes were unable to cause mortality over the time span of the experiment (Figures 3A and $3 \mathrm{~B})$. The mortality percentage decreased with increasing distance for 40,60 and $80 \mathrm{~cm}$. At the first two distances, the least larval mortality that occurred was $80 \%$ for both hosts when $H$. amazonensis was applied in the sand (Figure 3A and $3 \mathrm{~B}$ ). For the control treatment where only water was applied, there was no mortality caused by infective juveniles. Moreover, in the control treatment where larvae were not released, infective juvenile were extracted from sand until distance of $20 \mathrm{~cm}$ from the point they were applied. 

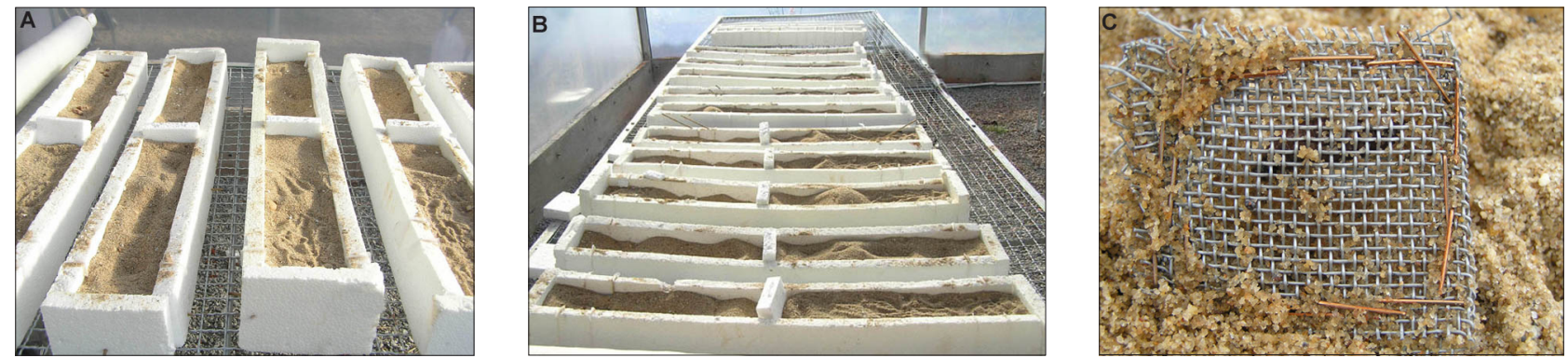

Figure 1 - Styrofoam enclosures to evaluate movement of Heterorhabditis amazonensis (A and B); cage with Galleria mellonella larvae (C).
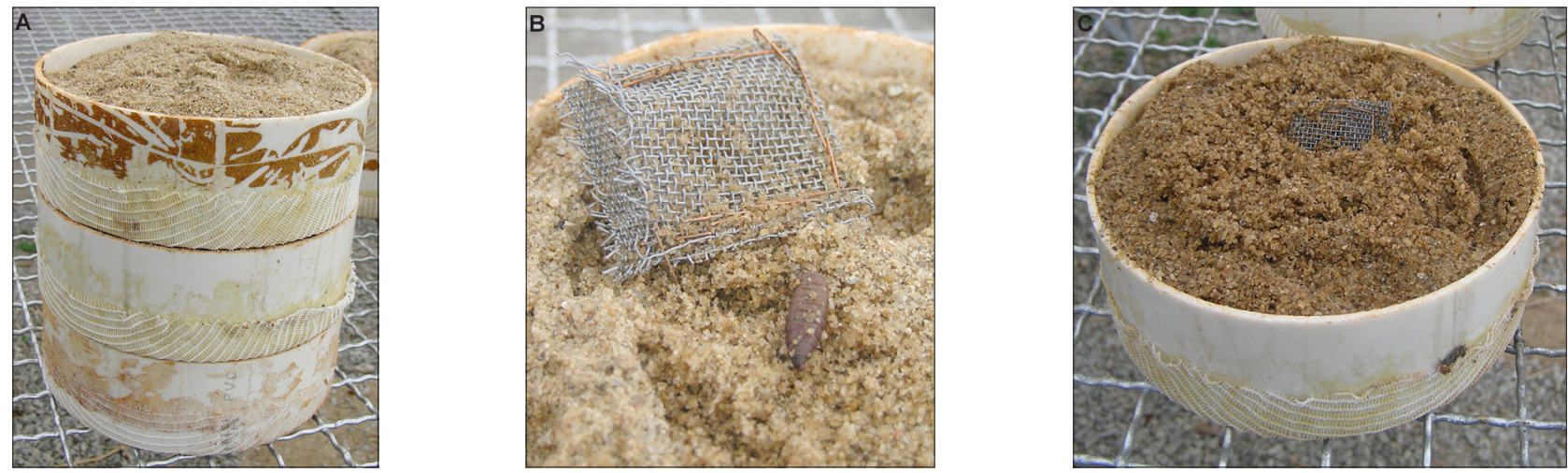

Figure 2 - Pieces of PVC pipe filled with a sand column to evaluate movement of Heterorhabditis amazonensis (A); PVC pipe and cage with Galleria mellonella larvae (B and C).
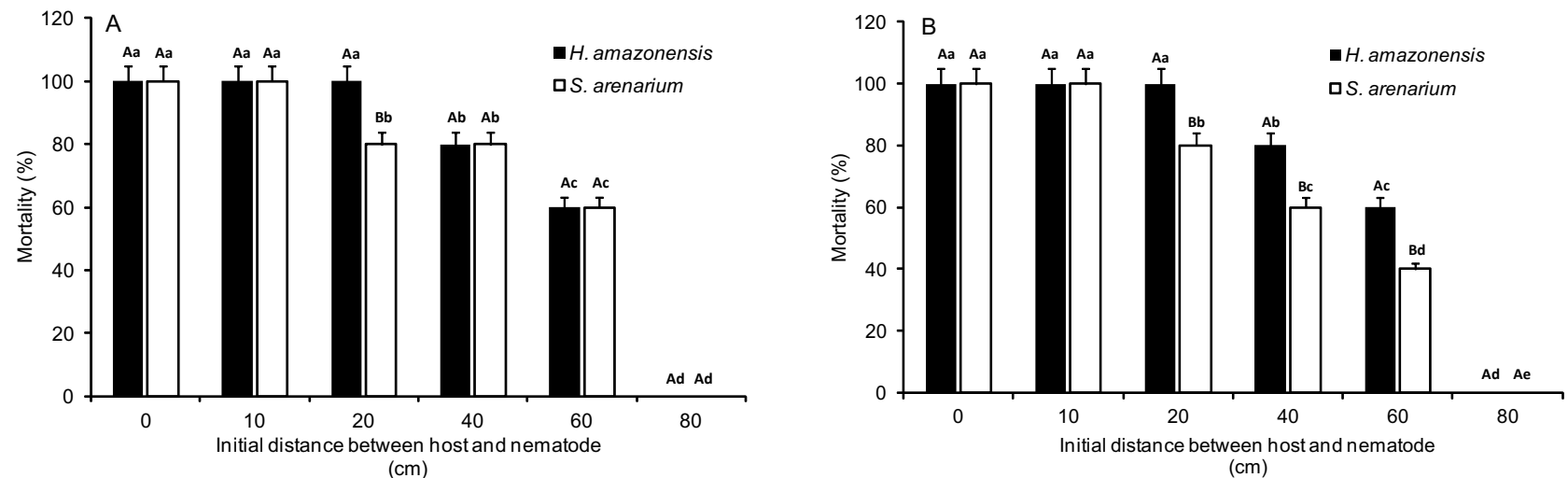

Figure 3 - Average mortality of the larvae of Galleria mellonella (A) and Spodoptera frugiperda (B) caused by the nematodes Heterorhabditis amazonensis RCS2 and Steinernema arenarium as a function of horizontal displacement in a sand enclosure. Same upper-case letters between nematodes for each distance and same lower-case letters in different distances for each nematode do not differ (Tukey test, $n=10 ; p<$ 0.05).

Heterorhabditis amazonensis caused mortality both in larvae of $G$. mellonella and in those of $S$. frugiperda. The $S$. arenarium nematode proved to be less pathogenic for S. frugiperda than $H$. amazonensis at 20,40 and 60 cm distances under our experimental conditions. At distances up to $60 \mathrm{~cm}$ from the host, the infective juveniles were capable of locating the host and causing its death. However, at $80 \mathrm{~cm}$ distance infective juveniles were not able to kill G. mellonella and S. frugiperda larvae. This re- sult demonstrates that $H$. amazonensis and $S$. arenarium are potentially able to find hosts.

\section{Vertical displacement in the sand column}

Pathogenicity data obtained for vertical displacement in the sand column were similar to those found in the horizontal displacement trial. Heterorhabditis amazonensis produced higher mortalities for both hosts than did S. arenarium. Steinernema arenarium produced more 
deaths among $G$. mellonella than among $S$. frugiperda larvae. Heterorhabditis amazonensis caused $100 \%$ mortality of the insect target $G$. mellonella up to a $10 \mathrm{~cm}$ distance and $90 \%$ mortality of $S$. frugiperda larvae. Steinernema arenarium caused $100 \%$ mortality of G. mellonella at 5 $\mathrm{cm}$ distance and $90 \%$ mortality of $S$. frugiperda at the same distance. At $10 \mathrm{~cm}$, this percentage decreased to a value lower than that found for $H$. amazonensis. At a distance of $25 \mathrm{~cm}$, both nematodes caused $40 \%$ mortality among the larvae tested (Figure 4A and 4B).

For the control treatment where no infective juvenile suspension was applied, there was no larval mortality. However, in the control treatment, in which no larvae were released, infective juveniles were extracted from sand until $15 \mathrm{~cm}$ from the top of the column. At $25 \mathrm{~cm}$ or less from the host, the infective juveniles were capable of locating the host and causing its death. This result demonstrates that $H$. amazonensis and $S$. arenarium are potentially able to find, infect and kill $S$. frugiperda larvae.

\section{Discussion}

The two nematode species caused different levels of mortality among the tested insects. Studies of these factors in species that were not studied previously are especially important. It would be incorrect to assume that phylogenetically related species necessarily exhibit the same behaviour patterns (Campbell et al., 2003; Lewis et al., 2006). The current study verified that $H$. amazonensis is capable of host search and of moving through the substrate for significant distances, finding the host at distances up to $60 \mathrm{~cm}$, as for $S$. arenarium.

According to Raulston et al. (1992) fall armyworm prepupae and pupae can suffer parasitism by Steinernema sp. accounting for $46.1 \%$ of mortality. However, the ability of these organisms to find the insect varies as a function of the distance between host and parasite, influ-

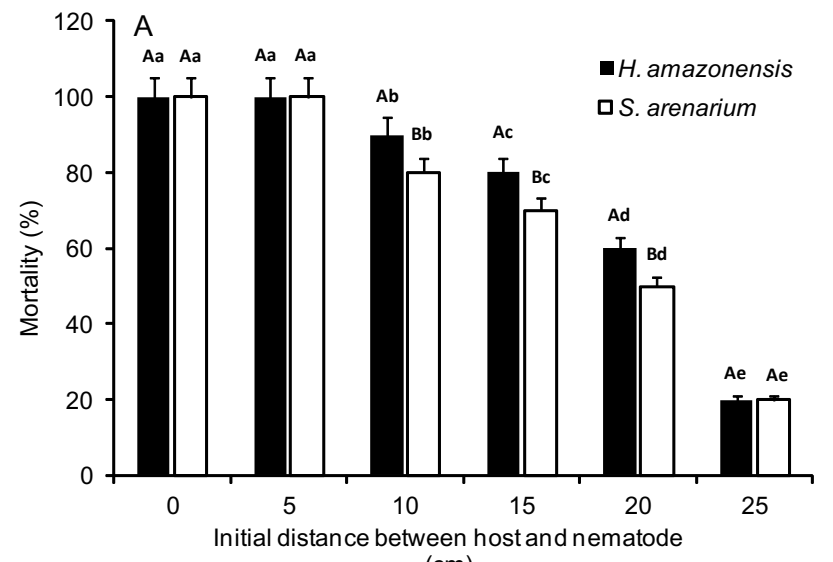

(cm) enced by soil characteristics and its moisture. It follows from these considerations that the EPN population considered adequate to control the pests should be selected before performing field trials in order to provide the best chance of obtaining infective juvenile populations that will be able to locate the insect target in its natural environment (Fuxa et al., 1988). Torr et al. (2004) also observed that the increase in distance from the host is accompanied by greater dilution of the chemical compounds, which means EPNs detect host compounds (and locate hosts) more easily when they are closer to the host. This fact is consistent with the results obtained in this study of $H$. amazonensis and $S$. arenarium with the hosts G. mellonella and S. frugiperda.

The infective juveniles can use environmental cues to locate the host. Some of these stimuli are the concentration of $\mathrm{CO}_{2}$ in the environment (Gaugler et al., 1980; Lewis et al., 1993; Lewis, 2002), the vibration caused by the host in the substrate (Torr et al., 2004), temperature gradients (Burman and Pye, 1980; Byers and Poinar Jr., 1982), the presence of an electric current (Shapiro-Ilan et al., 2009), and the presence of chemical compounds (Pye and Burman, 1981; Shapiro et al., 2000) such as the contents of the digestive tract of the insect (Grewal et al., 1997) and its excretion products (Schmidt and All, 1979; Grewal et al., 1993). The presence of these factors increases the chance of infective juveniles to find the host. In this study, as the horizontal or vertical distances increased, the strength of the environmental cues used by the EPN to find the host would tend to decrease.

In general, $H$. amazonensis demonstrated superior performance, measured by its ability to cause mortality of $S$. frugiperda and G. mellonella, than did S. arenarium under the tested conditions. This difference in performance appears to reflect a difference in the search capacity exhibited by the two studied EPNs; however, additional

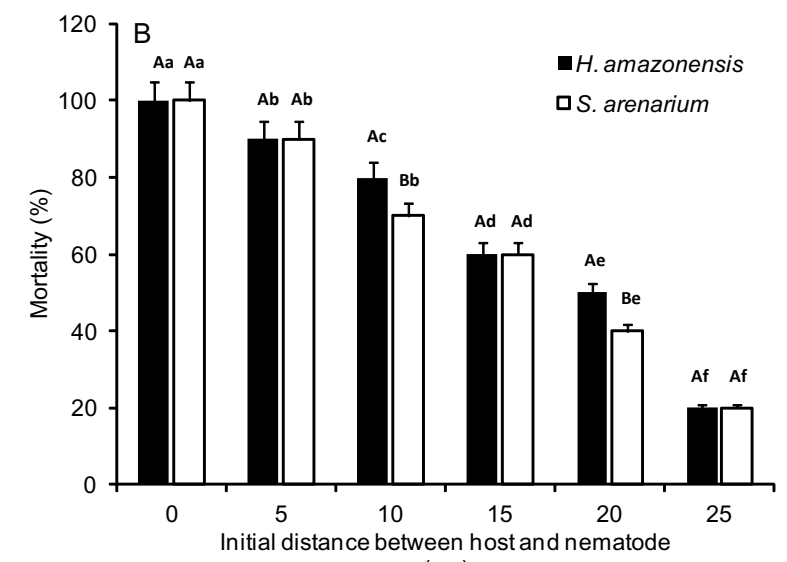

$(\mathrm{cm})$

Figure 4 - Average mortality of the larvae of Galleria mellonella (A) and Spodoptera frugiperda (B) caused by the nematodes Heterorhabditis amazonensis RCS2 and Steinernema arenarium as a function of vertical displacement in a sand column. Same upper-case letters between nematodes for each distance and same lower-case letters in different distances for each nematode do not differ (Tukey test, $\mathrm{n}=10 ; \mathrm{p}<$ 0.05). 
tests should be conducted to confirm the present results under more complex conditions.

A greater understanding of the behaviour of EPNs can lead to greater efficiency in utilizing them for the biological control of pests by helping to define the performance of these organisms against the insect pest. Greater insight into regulation of aspects of EPN behavior would also help in the evaluation of the potential impacts on non-target organisms and on the environment as a whole (Shapiro et al., 2000). These considerations clearly demonstrate the importance of understanding the behaviour of the EPNs for the purpose of evaluation of their ability to search for $S$. frugiperda, especially because various factors may have influence on this process. Additional tests in the field should be made to check the ability of these EPNs in finding $S$. frugiperda in natural conditions. The ultimate goal of such behavioural study is to guarantee the success and the efficiency of pest control using EPNs.

\section{Acknowledgements}

The authors thank FAPEMIG for financial support.

\section{References}

Adams, B.J.; Nguyen, K.B. 2002. Entomopathogenic nematology. p. 1-34. In: Gaugler, R., ed. Taxonomy and systematics. CABI, Wallingford, OX, UK.

Bowling, C.C. 1967. Rearing of two lepidopterous pests of rice on common artificial diet. Annals of the Entomological Society of America 60: 1215-1216.

Burman, M.; Pye, A. 1980. Neoaplectana carpocapsae:movement of nematode populations on a thermal gradient. Experimental Parasitology 49: 258-265.

Byers, J.A.; Poinar Jr., G.O. 1982. Location of insect hosts by the nematode Neoaplectana carpocapsae response to temperature. Behaviour 79: 1-10.

Campbell, J.F.; Lewis, E.E.; Stock, S.P.; Nadler, S.; Kaya, H.K. 2003. Evolution of host strategies in entomopathogenic nematodes. Journal of Nematology 35: 142-145.

Cutler, G.C.; Webster, J.M. 2003. Host-finding ability of three entomopathogenic nematode isolates in the presence of plant roots. Nematology 5: 601-608.

Dutky, S.R.; Thompson, J.V.; Cantwe, G.E. 1964. A technique for the mass propagation of the DD-136 nematode. Journal of Insect Pathology 6: 417-422.

Fuxa, J.R.; Richter, A.R.; Agudelo-Silva, F. 1988. Effect of host age and nematode strain on suceptibility of Spodoptera frugiperda to Steinernema feltiae. Journal of Nematology 20: 91-95.

Garcia, L.C.; Raetano, C.G.; Leite, L.G. 2008. Application technology for the entomopathogenic nematodes Heterorhabditis indica and Steinernema sp. (Rhabditida: Heterorhabditidae and Steinernematidae) to control Spodoptera frugiperda (Smith) (Lepidoptera: Noctuidae) in corn. Neotropical Entomology 37: 305-311.
Gaugler, R.; Lebeck, L.; Nakagaki, B.; Boush, M. 1980. Orientation of the entomogenous nematodes Neoaplectana carpocapsae to carbon dioxide. Environmental Entomology 9: 649-659.

Glazer, I. 2002. Survival biology. p. 169-187. In: Gaugler, R., ed. Entomopathogenic nematology. CABI, Wallingford, OX, UK.

Grewal, P.S.; Gaugler, R.; Lewis, E.E. 1997. Host recognition behaviour by entomopathogenic nematodes during contact with insect gut contents. Journal of Parasitology 79: 495-503.

Grewal, P.S.; Gaugler, R.; Selvan, S. 1993. Host recognition by entomopathogenic nematodes: behavioural response to contact with host feces. Journal of Chemical Ecology 19: 1219-1231.

Grewal, P.S.; Lewis, E.E.; Gaugler, R.; Campbell, J.F. 1994. Host finding behaviour as a predictor of foraging strategy in entomopathogenic nematodes. Parasitology 108: 207-215.

Kaya, H.K. 1990. Soil ecology. p. 93-115. In: Gaugler, R.; Kaya, H.K., eds. Entomopathogenic nematodes in biological control. CRC Press, Boca Raton, FL, USA.

Lewis, E.E. 2002. Behavioral ecology. p. 205-224. In: Gaugler, R., ed. Entomopathogenic nematology. CABI, Wallingford, OX, UK.

Lewis, E.E.; Campbell, J.; Griffin, C.; Kaya, H.; Peters, A. 2006. Behavioral ecology of entomopathogenic nematodes. Biological Control 38: 66-79.

Lewis, E.E.; Gaugler, R.; Harrison, R. 1992. Entomopathogenic nematode host finding: response to host contact cues by cruise and ambush foragers. Parasitology 105: 309-319.

Lewis, E.E.; Gaugler, R.; Harrison, R. 1993. Response of cruiser and ambusher entomopathogenic nematodes (Steinernematidae) to host volatile cues. Canadian Journal of Zoology 71: 765-769.

Molina, J.P.; López, N.J.C. 2001. In vivo production of three entomonematodes with two infection systems in two hosts. Revista Colombiana de Entomología 27: 73-78.

Parra, J.R.P. 1998. Raising insects for studies of pathogens. p. 10151037. In: Alves, S.B., ed. Microbial control of insects. FEALQ, Piracicaba, SP, Brazil.

Pye, A.E.; Burman, M. 1981. Neoaplectana carpocapsae: nematode accumulations on chemical and bacterial gradients. Experimental Parasitology 51: 77-81.

Raulston, J.R.; Pair, S.D.; Loera, J.; Cabanillas, H.E. 1992. Prepupal and pupal parasitism of Helicoverpa zea and Spodoptera frugiperda (Lepidoptera: Noctuidae) by Steinernema sp. in cornfields in the lower Rio Grande Vall ey. Journal of Economic Entomology 85: 1666-1670.

Schmidt, J.; All, J.N. 1979. Attraction of Neoaplectana carpocapsae (Nematoda: Steinernematidae) to common excretory products of insects. Environmental Entomology 8: 55-61.

Shapiro, D.I.; Lewis, E.E.; Paramasivam, S.; McCoy, C.W. 2000. Nitrogen partitioning in Heterorhabditis bacteriophora-infected hosts and the effects of nitrogen on attraction/repulsion. Journal of Invertebrate Pathology 76: 43-48.

Shapiro-Ilan, D.I.; Campbell, J.F.; Lewis, E.E.; Elkon, J.M.; KimShapiro, D.B. 2009. Directional movement of steinernematid nematodes in response to electrical current. Journal of Invertebrate Pathology 100: 134-137. 